\title{
Development and Validation of a TaqMan Real-Time PCR Assay for the Specific Detection and Quantification of Fusarium fujikuroi in Rice Plants and Seeds
}

\author{
Greice Amaral Carneiro, Slavica Matić, Giuseppe Ortu, Angelo Garibaldi, Davide Spadaro, and Maria Lodovica Gullino \\ First, second, third, fourth, fifth, and sixth authors: AGROINNOVA-Centre of Competence for the Innovation in the Agro-Environmental Sector, \\ Università di Torino, Largo P. Braccini 2, 10095 Grugliasco (TO), Italy; and fifth and sixth authors: Department of Agricultural, Forestry and \\ Food Sciences (DISAFA), Università di Torino, Largo P. Braccini 2, 10095 Grugliasco (TO), Italy. \\ Accepted for publication 1 April 2017.
}

\begin{abstract}
Bakanae disease, which is caused by the seedborne pathogen Fusarium fujikuroi, is found throughout the world on rice. A TaqMan real-time PCR has been developed on the TEF $1-\alpha$ gene to detect $F$. fujikuroi in different rice tissues. Three primer/probe sets were tested. The selected set produced an amplicon of $84 \mathrm{bp}$ and was specific for $F$. fujikuroi with respect to eight Fusarium species of rice and six other rice common pathogens. The assay was validated for specificity, selectivity, sensitivity, repeatability, and reproducibility. The detection limit was set at $27.5 \mathrm{fg}$ of DNA, which is approximately equivalent to one haploid genome of $F$. fujikuroi.

The developed TaqMan real-time assay was able to efficiently detect and quantify $F$. fujikuroi from rice culms, leaves, roots, and seeds. At 1 week post-germination (wpg), the pathogen was more diffused in the green tissues, while at 3 wpg it was uniformly spread also in the roots. The highest concentration of $F$. fujikuroi was measured in the M6 cultivar, which showed around 1,450 fungal cells/g. The assay was sufficiently sensitive to detect a few genomic equivalents in the rice seeds, corresponding to $9.89 \mathrm{~F}$. fujikuroi cells/g. The assay permitted bakanae disease to be detected in asymptomatic tissues at the early rice development stages.
\end{abstract}

Bakanae is a rice seedborne disease that poses a serious threat to rice cultivation (Webster and Gunnell 1992). The disease is caused by Fusarium fujikuroi Nirenberg [teleomorph Gibberella fujikuroi (Sawada) Ito in Ito \& K. Kimura], a member of the polyphyletic taxon G. fujikuroi species complex (GFSC) (Carter et al. 2008; Desjardins et al. 1997; O'Donnell et al. 1998). The most common symptoms are bakanae tillers, which are highly elongated and can be observed over a distance in fields and seedbeds, due to the high level of gibberellins released by the pathogen (Stowe and Yamaki 1957). Diseased plants appear to be abnormally tall, thin, and yellowish compared with other plants. Severely infected seedlings show necrotic root tissue and frequently die either before or after transplanting (Misra et al. 1994). Since bakanae was first reported in Japan (1928), the disease has spread widely across Asia, causing important yield losses in Pakistan, Malaysia, Indonesia, Bangladesh, India, South Korea, Taiwan, Philippines, and Thailand (Gupta et al. 2015; Jeon et al. 2013). Yield losses have increased in Italy, the main European rice producer (Spadaro et al. 2016). Bakanae disease has also been reported in California (Carter et al. 2008), Russia (Jeon et al. 2013), and Macedonia (Karov et al. 2009).

Seed treatments against seedborne fungal pathogens include the application of fungicides, physical treatments, biocontrol agents, antimicrobial plant extracts, and essential oils (Tinivella et al. 2009). All of these methods have been reported for $F$. fujikuroi control on rice seeds (Matić et al. 2014; Titone et al. 2004). Despite the recent development of new control methods, the management of bakanae disease remains difficult, due to its extensive geographical distribution and increasing incidence. The reduction in pesticide availability and the occurrence of fungicide resistance has increased the severity

Corresponding author: D. Spadaro; E-mail address: davide.spadaro@unito.it

First and second authors contributed equally to the work.

(C) 2017 The American Phytopathological Society of the disease in Europe (Matić et al. 2016; Spadaro et al. 2016), with consequent serious issues for seed companies that need to supply growers with rice seeds that are certified to be free from F. fujikuroi.

Identification of Fusarium spp. on the basis of an observation of the visible symptoms or morphological characteristics after fungal isolation and on the basis of the culture is complicated and timeconsuming (Leslie and Summerell 2006). The microscope discrimination of Fusarium spp. within the GFSC, which includes F. fujikuroi, $F$. proliferatum, $F$. verticillioides, and $F$. andiyazi, can lead to certain limitations due to their very similar morphological traits (O'Donnell et al. 1998). An accurate detection and identification of $F$. fujikuroi is necessary for the management of bakanae disease and to evaluate the rice resistance germplasm. Like other disease assessments, the evaluation of bakanae disease depends on the presence of visible symptoms (Hwang et al. 2013; Ou 1985). Although this method is useful during bakanae development in the field, it is not useful for early disease detection and control at the initial disease stages or for fungal quantification in infected rice tissues. Pathogen detection, based on symptomatology and morphological criteria, is possible at later stages, but this might result in an ineffective disease control and a further spreading of the pathogen. On the other hand, molecular diagnostics of plant pathogenic fungi is characterized by high specificity, sensitivity and early detection (Capote et al. 2012).

Real-time PCR has been used in plant pathology for DNA quantification and the diagnosis of several plant pathogens (Deepak et al. 2007; Mirmajlessi et al. 2015). It offers many advantages over conventional PCR, including speed, sensitivity, specificity, reproducibility, and quantification (Smith and Osborn 2009). Real-time PCR exploits different fluorescence-measurement approaches for DNA amplification: (i) DNA-binding dyes, such as SYBR green I; (ii) hydrolysis or TaqMan probes, which exploit the 5 '-exonuclease activity of Taq DNA polymerase; and (iii) hybridization probes, which utilize donor and acceptor fluorophores (Valasek and Repa 2005). Although real-time PCR using an SYBR green dye was previously developed for the detection of $F$. fujikuroi from different rice tissues 
(Amatulli et al. 2012), it was not able to quantitatively and reliably detect $F$. fujikuroi from seeds, and this led to the development of a more sensitive molecular diagnostic tool.

The aim of this study was to develop a TaqMan real-time PCR for $F$. fujikuroi identification and quantification in infected rice materials. The sensitivity, specificity, selectivity, repeatability, and reproducibility of the assay were validated. The relationship between symptom progression and F. fujikuroi occurrence was explored in different rice tissues, including the leaves with culms, roots, and naturally infected seeds from six different cultivars.

\section{MATERIALS AND METHODS}

Fungal isolates. Thirty-five isolates of $F$. fujikuroi and of eight other Fusarium spp. were used in this study. Furthermore, 11 isolates of six common rice pathogenic fungi (Magnaporthe oryzae, M. salvinii, Rhizoctonia solani, Cochliobolus miyabeanus, Gaeumannomyces graminis, and Alternaria padwickii) (Table 1). All isolates of $F$. fujikuroi were from the Agroinnova collection (University of Torino, Italy), with the exception of $F$. fujikuroi M-1149 (Fusarium Research Centre, Pennsylvania State University), $F$. proliferatum ITEM1720, and $F$. verticillioides ITEM1746
(Institute of Sciences and of Food Production, Bari, Italy). The fungal isolates were stored long term at $-80^{\circ} \mathrm{C}$ in $20 \%$ glycerol.

DNA extraction from fungal cultures. The total DNA of all the fungal species was extracted with an E.Z.N.A. Fungal DNA Mini Kit (Omega Bio-Tek, Darmstadt, Germany) from $0.1 \mathrm{~g}$ of mycelium grown on potato dextrose agar (Merck $\mathrm{KGaA}$ ), according to the manufacturer's instructions. The quality and concentration of DNA were measured using a NanoDrop 2000 Spectrophotometer (Thermo Scientific, Wilmington, DE), and the DNA was serially diluted to concentrations ranging from $1 \mathrm{ng}$ to $1 \mathrm{fg}$ per $\mu \mathrm{l}$.

Sequence analyses, TEF 1- $\alpha$ amplification, and probe design. Sequences of the TEF 1- $\alpha$ gene were selected and aligned for nine Fusarium spp. available in GenBank (F. fujikuroi GQ848522, GQ848524, and HM243234; $F$. proliferatum GQ848533; $F$. verticillioides GQ848532; $F$. andiyazi HM243238; F. napiforme GQ848547; F. culmorum JN092353; F. graminearum GQ848545; F. equiseti GQ848541; and F. oxysporum GQ848538). The portions of the sequences that were specific to $F$. fujikuroi, that is those including six-nucleotide deletion, were used to select potential primers and a TaqMan probe for real-time PCR. The primers and probe were designed by means of Primer Express 3.0 software (Applied Biosystems, Foster City, CA). Three sets of primers paired with a probe were selected to predict amplicons ranging from 84 to

TABLE 1. Representative Fusarium spp. and other fungal species tested by means of TaqMan real-time PCR

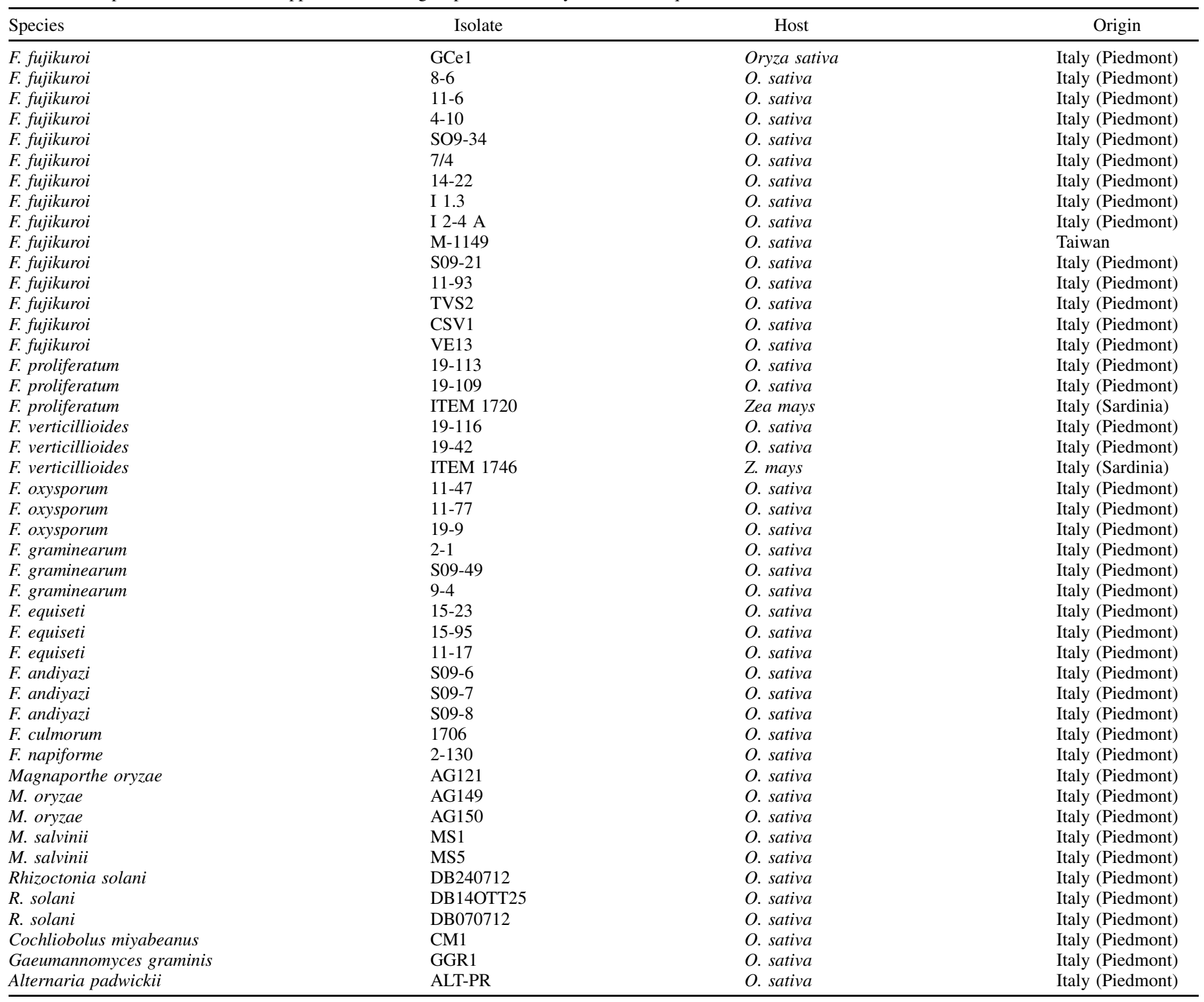


116 bp (Table 2). The TaqMan probe was labeled with the 6-carboxy-fluorescein dye (6-FAM) fluorescent reporter at the 5 '-end, and the nonfluorescent quencher-minor groove binder (NF-MGB) at the $3^{\prime}$-end (Applied Biosystems). A primer-probe combination, targeting a highly conserved region of the fungal $18 \mathrm{~S}$ ribosomal DNA, was used as the exogenous control.

Real-time PCR optimization. A real-time PCR assay was performed in a $20-\mu \mathrm{l}$ reaction in triplicate. Various concentrations of the primers $(0.2$ to $0.8 \mu \mathrm{M})$ and probe $(0.1$ to $0.3 \mu \mathrm{M})$ were tested in different combinations. Amplification was performed in 96-well Optical Reaction Plates (Applied Biosystems) sealed with a MicroAmp Optical Adhesive Film, on a StepOnePlus real-time PCR system (Applied Biosystems). The optimized real-time PCR mixture and conditions involved the application of a TaqMan Master Mix $(2 \times)$ (Applied Biosystems), two $0.5 \mu \mathrm{M}$ primers, the TaqMan probe at $0.25 \mu \mathrm{M}$, and $2 \mu \mathrm{l}$ of DNA with an incubation at $50^{\circ} \mathrm{C}$ for $2 \mathrm{~min}$ and at $95^{\circ} \mathrm{C}$ for $10 \mathrm{~min}$, followed by 40 cycles of $15 \mathrm{~s}$ at $95^{\circ} \mathrm{C}$ and $1 \mathrm{~min}$ at $62^{\circ} \mathrm{C}$.

Specificity, selectivity, sensitivity, repeatability, and reproducibility of the real-time PCR. Genomic DNA from nine different species of Fusarium and from six rice pathogens was analyzed to evaluate the specificity of the real-time PCR assay for $F$. fujikuroi. After 40 cycles, each real-time PCR reaction was evaluated to establish the presence or absence of an amplification signal. The potential influence of the matrix (rice and soil microbiota) on the selectivity of real-time PCR amplifications was evaluated in different experiments. Three strains of F. fujikuroi (14-22, 11-93, and M-1149 with accession numbers GQ848524, GQ848522, and HM243234) were used to determine the sensitivity and linear range of the assay. Serial dilutions of genomic DNA from these strains were used (275 ng, $27.5 \mathrm{ng}, 2.75 \mathrm{ng}, 275 \mathrm{pg}, 27.5 \mathrm{pg}, 2.75 \mathrm{pg}, 275 \mathrm{fg}$, and $27.5 \mathrm{fg}$ ). Each sample was amplified in triplicate, and the entire experiment was repeated eight times (EPPO 2014). The experiments were reproduced in two distinct laboratories.

Detection of $\boldsymbol{F}$. fujikuroi from rice plants. Six rice cultivars (Oryza sativa L. 'Selenio', 'Graldo', 'Greppi', 'Handao 297', 'M6', and 'Dorella') were selected for F. fujikuroi detection. A conidial suspension $\left(10^{6}\right.$ conidia/ml) of a highly pathogenic $F$. fujikuroi strain (M-1149) grown in potato dextrose broth (Merck KGaA, Darmstadt, Germany) was used for the artificial inoculation of the rice. Rice inoculation was carried out as previously described (Matić et al. 2013). Rice seeds of each cultivar were briefly surface-disinfected in $1 \%$ sodium hypochlorite and then rinsed in sterile distilled water. A set of 40 seeds was soaked in a $100-\mathrm{ml}$ spore suspension in triplicate, and shaken for $30 \mathrm{~min}$ at room temperature. The control seeds were soaked in sterile distilled water. The seeds were sown in plastic pots in a sterile mixture of peat and sand (60\%:40\%) with three replicates, and the plants were grown in a greenhouse under controlled temperature conditions $\left(25^{\circ} \mathrm{C}\right.$ day: $17^{\circ} \mathrm{C}$ night $)$ with watering three times in $24 \mathrm{~h}$. The germination rate and disease index were evaluated 3 weeks post-germination (wpg), using a five-point scale of the symptoms: (0) asymptomatic plants, (1) plants with yellow leaves, (2) plants with long internodes, (3) necrotic plants, and (4) dead plants (Amatulli et al. 2010). Culms with leaves, and roots were collected at 1 and 3 wpg for the molecular experiments. The DNA was extracted from $0.1 \mathrm{~g}$ of fresh plant material that was ground with liquid nitrogen. The powder resulting from the grinding was transferred into a 1.5-ml microcentrifuge tube, to which a $600 \mu \mathrm{l}$ of P1 buffer of E.Z.N.A. Plant DNA Kit (Omega Bio-Tek) was added, and was then vortexed and incubated at $65^{\circ} \mathrm{C}$ for $10 \mathrm{~min}$. Finally, the extracted DNA from rice tissues was eluted in a $30-\mu$ l elution buffer. The quality and concentration of DNA were measured as previously described.

Quantification of $\boldsymbol{F}$. fujikuroi. Quantification of the pathogen in the plants was measured by extracting DNA from aerial and roots of six rice cultivars that showed different levels of susceptibility to F. fujikuroi. The DNA quantity of the target (from three technical replicates per sample) was used to calculate the approximate number of $F$. fujikuroi cells present in each sample, through the following formula: number of cells $/ \mu \mathrm{l}=\mathrm{DNA}$ quantity $/ 0.000048$. The number 0.000048 refers to the weight of a $F$. fujikuroi genome expressed in ng (Jeong et al. 2013; Wiemann et al. 2013), and the number of cells to haploid Fusarium cells (Ruiz-Roldán et al. 2010). This formula allows the number of fungal cells per microliter of reaction mix to be found. However, the initial weight of the sample was also taken into consideration (e.g., $0.1 \mathrm{~g}$ ), and the number of F. fujikuroi cells per milligram of rice tissue was therefore calculated by multiplying the cells by the volume of extracted DNA in microliters, and dividing the value by the initial weight of the rice sample $(0.1 \mathrm{~g})$.

Detection of $\boldsymbol{F}$. fujikuroi from rice seeds. The TaqMan realtime PCR assay was conducted on naturally infected seed lots of the six tested rice cultivars. Each lot contained 1,000 seeds (divided in two technical replicates) and that quantity is higher than the standard working sample (400 seeds) for rice seed health testing (ISTA 1985; Mojica and Gomez 1994). The DNA extraction from the seeds was performed on a $0.1 \mathrm{~g}$ fraction of 1,000 seeds and ground with liquid nitrogen. The resulting powder was extracted with the E.Z.N.A. Plant DNA Kit, as previously described.

Data analysis. Baseline range, threshold cycle $\left(C_{T}\right)$ values, and real-time PCR standard curves were automatically generated using StepOne software. Statistical analyses of the data were performed with the Statistical Package for Social Science (SPSS, IBM, Chicago, IL) version 21.0.

\section{RESULTS}

Probe and primer development. The TEF 1- $\alpha$ gene was chosen as a specific region, due to the deletion of six nucleotides that had previously only been found in F. fujikuroi (Amatulli et al. 2012). TEF 1 - $\alpha$ sequences from different isolates of nine Fusarium spp. were aligned and three primer/probe sets were designed (Table 2). The combination of probe and primer sets was tested in quantitative PCR (qPCR), under different cycling conditions and probe/primer concentrations to evaluate their ability to specifically detect $F$. fujikuroi. In order to increase the stringency and to avoid false positive results, the annealing/extension temperature was optimized to $62^{\circ} \mathrm{C}$. After examination of the amplification results, the FfujiPq probe and $\mathrm{TqF} 2 /$ TqR primer pair were selected as the best candidates for the TaqMan real-time PCR assay.

TaqMan probe specificity, selectivity, sensitivity, repeatability, and reproducibility. As far as the specificity of Taqman qPCR is concerned, the FfujiPq and TqF2/TqR probe/primer combination was able to repeatedly and reliably amplify the 84-bp DNA fragment from different strains of $F$. fujikuroi, but not from eight other species of Fusarium or from six additionally tested rice pathogens. The presence of plant and/or soil microbial DNA together with the fungal DNA did not influence the selectivity of the TaqMan probe (FfujiPq) in the qPCR assays.

TABLE 2. Primer and probe sets used in TaqMan PCR for Fusarium fujikuroi detection

\begin{tabular}{lcl}
\hline $\begin{array}{l}\text { Primers and } \\
\text { TaqMan probe }\end{array}$ & $\begin{array}{c}\text { Amplicon } \\
(\mathrm{nt})\end{array}$ & \multicolumn{1}{c}{ Sequence $\left(5^{\prime}-3^{\prime}\right)$} \\
\hline TqF2 & & GGCGCGTTTTGCCCTTTCCT \\
TqR & 84 & AGCGGCTTCCTATTGTCGAA \\
FfujiPq & & $\begin{array}{l}\text { [FAM]-TCACGTGTCAAACTAAA- } \\
\text { [NF-MGB] }\end{array}$ \\
TqF1 & & CGAGTGATGGGCGCGTTTTG \\
TqR & 93 & AGCGGCTTCCTATTGTCGAA \\
TaqFuji & & [FAM]-CGCATTGTCACGTGTCAAAC- \\
& & [NF-MGB] \\
FfujiFq & \multirow{2}{*}{ CACGTGTCAACTAAACATTCG } \\
FfujiRq & 116 & GATGGTGATACCACGCTCAC \\
BakanPq & & [FAM]-GCCGCTGAGCTCGGTAAGGG- \\
& & [NF-MGB] \\
\hline
\end{tabular}


The detection limit and dynamic range of the qPCR reaction were determined from the standard curve using DNA extracted from a pure culture of three F. fujikuroi strains (14-22, 11-93, and M-1149). A standard regression line was generated for each DNA standard curve, using a range of DNA from $10 \mathrm{ng}$ to $0.1 \mathrm{pg}$. High sensitivity was achieved over 5 orders of magnitude of DNA concentration that exhibited a linear dynamic range of amplification. F. fujikuroi DNA (from both the pure fungal cultures and rice tissues) was quantified accurately up to a concentration of $27.5 \mathrm{fg}$, with a $\mathrm{C}_{\mathrm{T}}$ range of between 31 and 34 . The detection limit of $27.5 \mathrm{fg}$ of DNA is lower than a weight of a single haploid genome of $F$. fujikuroi ( $48 \mathrm{fg}$ of DNA).

The correlation coefficients between the $\mathrm{C}_{\mathrm{T}}$ value and the amount of genomic DNA of all three strains were high $\left(R^{2}>0.99\right)$, and the regression slopes were $-3.34,-3.14$, and -3.12 (for the strains 11-93, 14-22, and M-1149, respectively). The corresponding slopes were within a slope range of between -3.58 and -3.10 , which approved good qPCR efficiency (between 90 and 110\%; Adams, 2006). As expected, the three standard curves overlapped almost completely with a high degree of repeatability (Fig. 1) and the slight differences could be related to the DNA extraction that could be influenced by the secondary metabolite profile (Zhang et al. 2010). The assay was performed on various days by two different operators in two different laboratories in order to confirm its reproducibility.

Detection and quantification of $F$. fujikuroi in rice culms, leaves, and roots. One experiment was performed in vivo on six rice cultivars to evaluate the presence of $F$. fujikuroi on rice culms with leaves and roots at different points of time. At $1 \mathrm{wpg}$, none of the cultivars showed visible symptoms. The typical symptoms of bakanae, such as abnormal stem elongation and increase of the leaf insertion angle started to occur on the Dorella, Handao 297, and M6 rice cultivars later on. These latter cultivars showed the most severe symptoms at 3 wpg (Fig. 2), while most plants were withered and dead at $4 \mathrm{wpg}$, and showed drastically inhibited root growth. All the plants of the M6 cultivar were already dead at 3 wpg (Table 3). The Dorella, Handao 297, and M6 cultivars were considered susceptible. On the contrary, the Selenio, Graldo, and Greppi cultivars did not show any typical bakanae symptoms throughout the whole experiment, and only a small number of yellowish plants could be observed (Fig. 2).

$F$. fujikuroi was detected at $1 \mathrm{wpg}$ (asymptomatic period) by the TaqMan qPCR assay in both susceptible and resistant cultivars, and its presence was higher in the aerial parts than in the roots (Fig. 3). At 3 wpg, when the most notable bakanae symptoms occurred, the concentration was higher in both the aerial and root parts of the susceptible cultivars, while it was lower in the culms and leaves of the resistant cultivars (Fig. 3; Table 3). Interestingly, cultivars Handao 297 and Dorella exhibited slightly higher concentrations of $F$. fujikuroi in the aerial parts of the plant, while M6 exhibited a higher concentration in the roots. The highest concentration of $F$. fujikuroi was measured in the roots of the most susceptible cultivar M6, with around 1,450 fungal cells per gram of tissue (Fig. 3). The resistant cultivars (Greppi, Graldo, and Selenio) showed a much lower presence of $F$. fujikuroi (from 279 to 0.3 cells per gram of plant tissue), mainly in the aerial parts of the plants, than the susceptible cultivars, in the initial infection period.

Detection and quantification of $F$. fujikuroi in rice seeds. The TaqMan qPCR assay was also used to detect and quantify F. fujikuroi in naturally contaminated rice seed lots of six rice cultivars. Mixed populations of Fusarium spp. could occur in rice seeds, but the TaqMan FfujiPq PCR amplification was specific and was therefore not influenced by other Fusarium species or by the presence of rice genomic DNA. This qPCR was sufficiently sensitive to detect 9.89 F. fujikuroi cells/g of naturally infected rice seed lots (Fig. 4). The F. fujikuroi DNA from the seeds was quantified precisely up to the same concentration of the other rice tissues $(27.5 \mathrm{fg})$ and a $\mathrm{C}_{\mathrm{T}}$ range between 34 and 36 .

\section{DISCUSSION}

The method developed in this study has allowed a fast $F$. fujikuroi identification at the early stages of the disease, and a reliable

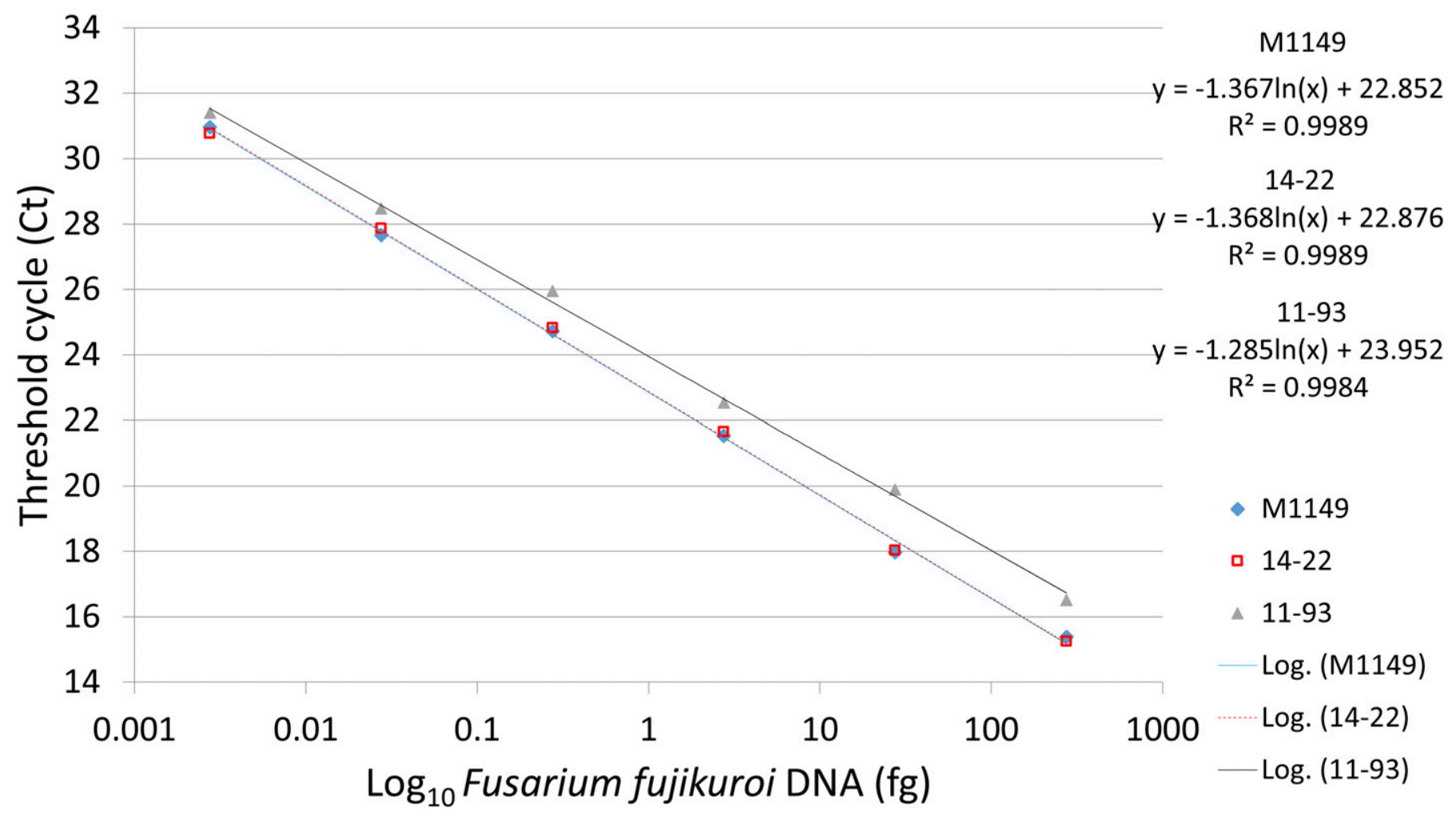

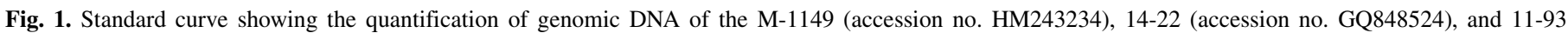

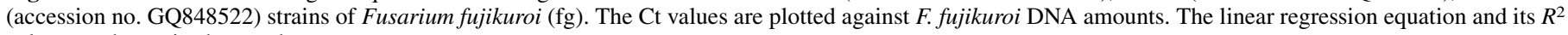
value are shown in the graph. 

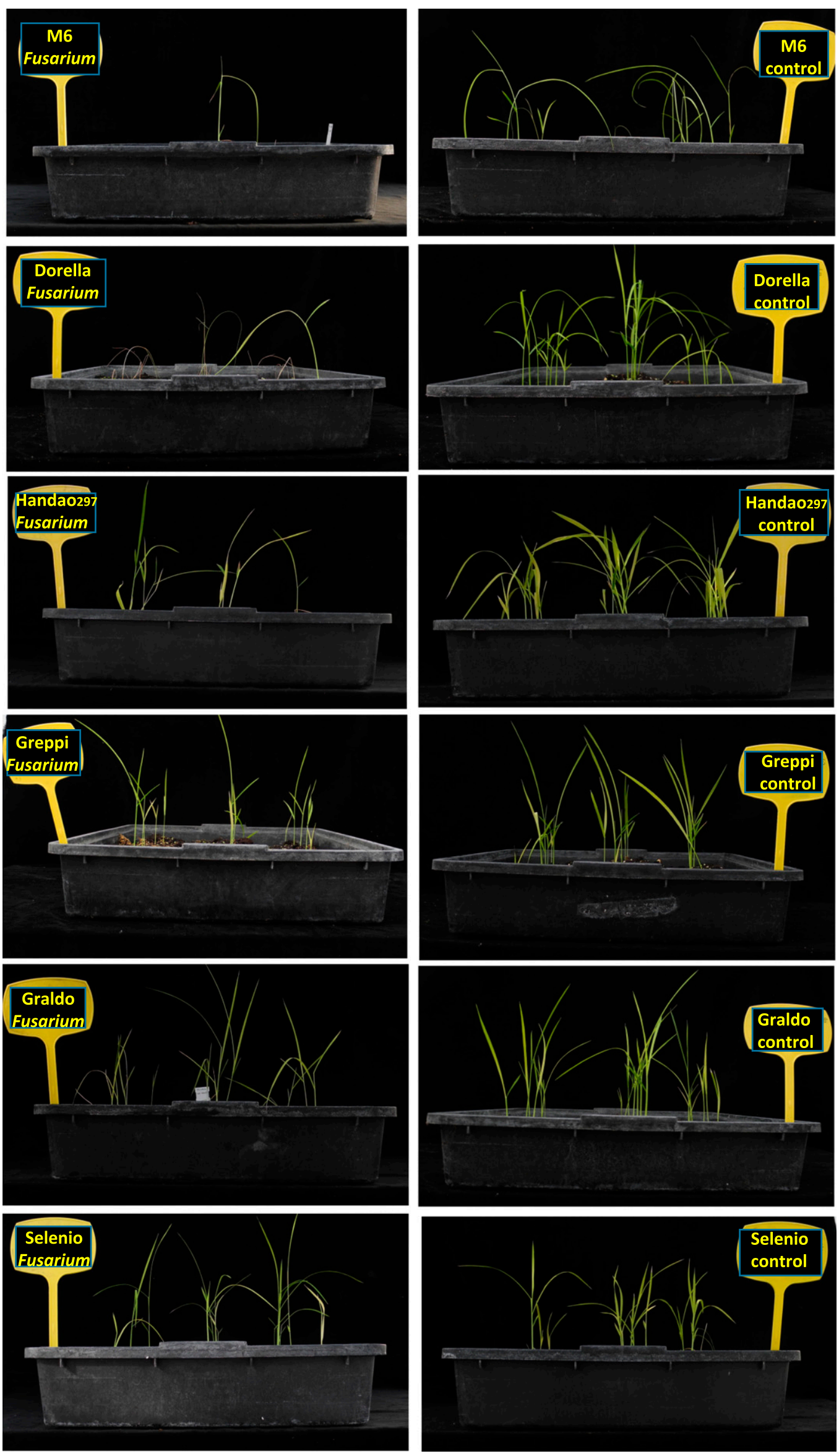

Fig. 2. Pathogenicity tests on rice plants of six cultivars artificially inoculated with Fusarium fujikuroi at 3 weeks post-germination. 
quantification from different rice materials, including the seeds, where the fungus is present at a lower concentration (Dieter 2002). It could be applied to DNA extracted directly from rice seeds or fresh plant tissues, and it is not affected by a nonspecific background from coextracted plant DNA, soil microbial DNA, or from other Fusarium spp. associated with bakanae disease or commonly present on rice (Desjardins et al. 2000; Wulff et al. 2010). The probe and primers were evaluated by amplifying the DNA from pure culture isolates of Fusarium spp., and the specificity was assessed by means of a specific amplification of DNA from F. fujikuroi, and not from other Fusarium spp. The method was also tested on six common pathogenic species of rice, without any amplification signal. Most of the tested Fusarium spp. are members of the GFSC and can be distinguished morphologically from $F$. fujikuroi according to the microconidia production and absence of chlamydospores. However, other Fusarium species, such as $F$. proliferatum and $F$. verticilloides, would need expertise in Fusarium taxonomy to be differentiated from F. fujikuroi (Leslie et al. 2004). The increased stringency of the amplification reaction developed in the present study, which was obtained by increasing the annealing temperature to $62^{\circ} \mathrm{C}$, avoided the problem of crossamplification and allowed $F$. fujikuroi to be specifically detected.

TABLE 3. Disease index and germination of six rice cultivars inoculated $(+)$ or not inoculated (-) with Fusarium fujikuroi at 3 weeks post-germination ${ }^{\mathrm{a}}$

\begin{tabular}{lcc}
\hline Cultivar $^{\mathrm{b}}$ & Disease index $(\%)$ & Germination $(\%)$ \\
\hline Selenio + & 7.5 & 93.2 \\
Selenio - & 0.0 & 95.8 \\
Graldo + & 7.5 & 87.7 \\
Graldo - & 0.0 & 96.7 \\
Greppi + & 12.5 & 83.3 \\
Greppi - & 0.0 & 89.2 \\
Dorella + & 87.5 & 40.2 \\
Dorella - & 0.0 & 95.4 \\
Handao 297 + & 72.5 & 55.0 \\
Handao 297 - & 0.0 & 98.3 \\
M6 + & 100.0 & 41.1 \\
M6 - & 17.2 & 90.4
\end{tabular}

a Forty seeds per variety were tested in three replicates per treatment. The experiments were carried out three times.

b Three resistant (Selenio, Graldo, and Greppi) and three susceptible (Dorella, Handao 297, and M6) rice cultivars were evaluated.
Additionally, the sensitivity was not impaired by the increased stringency, thus permitting the detection of up to $27.5 \mathrm{fg}$ of $F$. fujikuroi in both the rice plants and seeds.

The additional specificity provided by the internal probe is advantageous in overcoming the risks of false positives and negatives. Since SYBR Green nonspecifically binds any double-stranded DNA that is present in a real-time PCR reaction, our protocol was based on a more specific TaqMan probe. Moreover, the Taq DNA polymerase can be inhibited by SYBR Green, which limits the fluorescence signal and the sensitivity of the assay (Kermekchiev et al. 2009). This issue was also overcome by using the TaqMan probe, which increased the sensitivity of the assay and reduced the necessary amount of the Taq enzyme.

After optimizing the PCR conditions, in order to achieve the highest specificity, the protocol was implemented for quantitative purposes. After the quantification of $F$. fujikuroi DNA from a pure culture, the utility of the quantification protocol was checked in different rice tissues. It was found that the sensitivity of the qPCR protocol was not affected by the nature of the sample, since the fungus could be detected and quantified in complex naturally infected matrices of diverse origin, including different plant tissues and soil residues. Our results showed fungal presence in both the aerial tissues and roots of infected rice plants, without any visible symptoms during the early stage of bakanae disease. Furthermore, a successful amplification of $F$. fujikuroi was obtained by TaqMan qPCR from naturally infected rice seeds with a high starch level (one of the main polysaccharides), insoluble phenolic compounds, and other interfering substances (Tian et al. 2004; Wang et al. 2012). Polysaccharides can be especially troublesome inside DNA extracts, since their presence is inhibitory to Taq polymerase activity (Fang et al. 1992). Polyphenolic compounds may bind to DNA during cell lysis, and may be recalcitrant to further enzymatic manipulations (John 1992). In the present study, no inhibition of Taq DNA polymerase was observed after the application of the developed TaqMan real-time PCR assay. Hence, the purity of the DNA extracts from rice seeds obtained with the E.Z.N.A. DNA Kit had a higher $\mathrm{A}_{260 / 280}$ ratio than 1.8 and a higher $\mathrm{A}_{260 / 230}$ ratio than 2, thus indicating little or no DNA contamination by proteins, polyphenolics, or polysaccharides. Moreover, it was above the amenable DNA purity limit for molecular studies (Sambrook and Russell 2001).

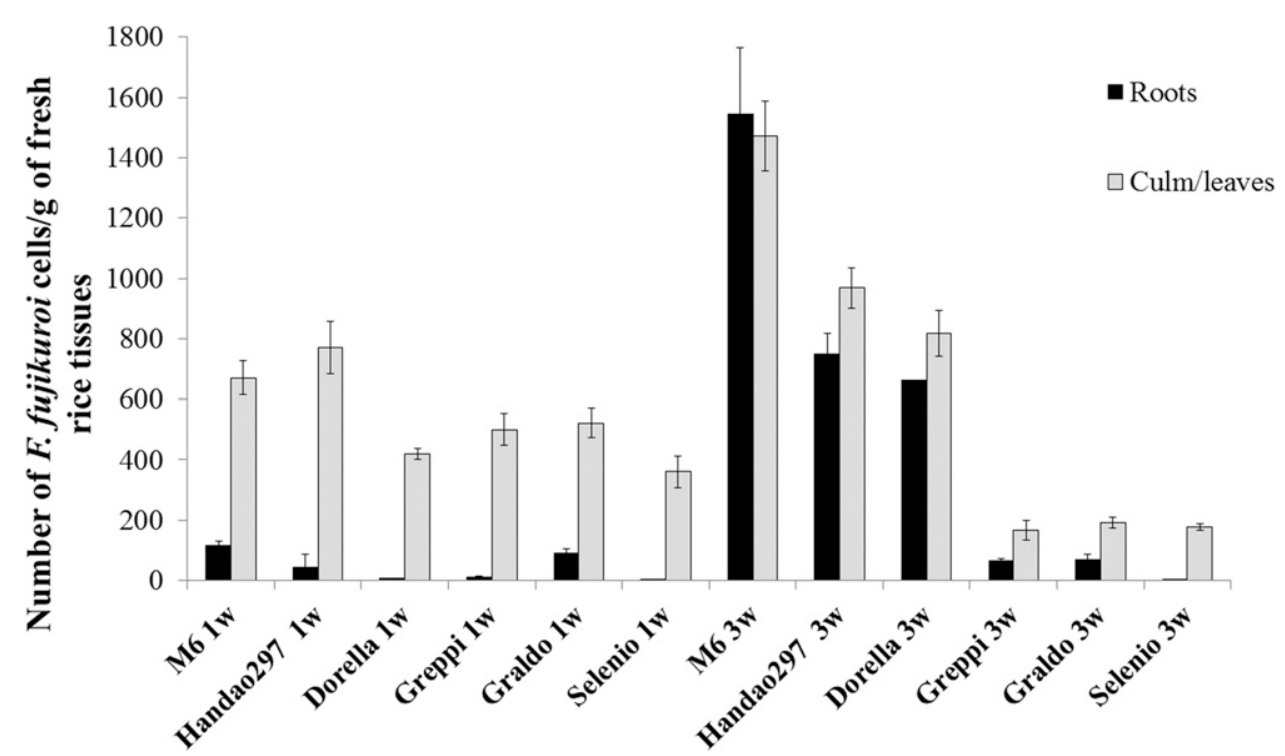

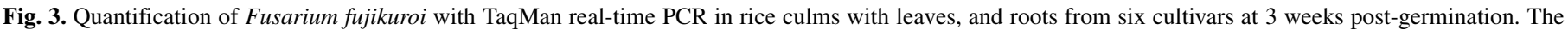
values are the means \pm standard deviation ( $n=9$ independent analyses). 


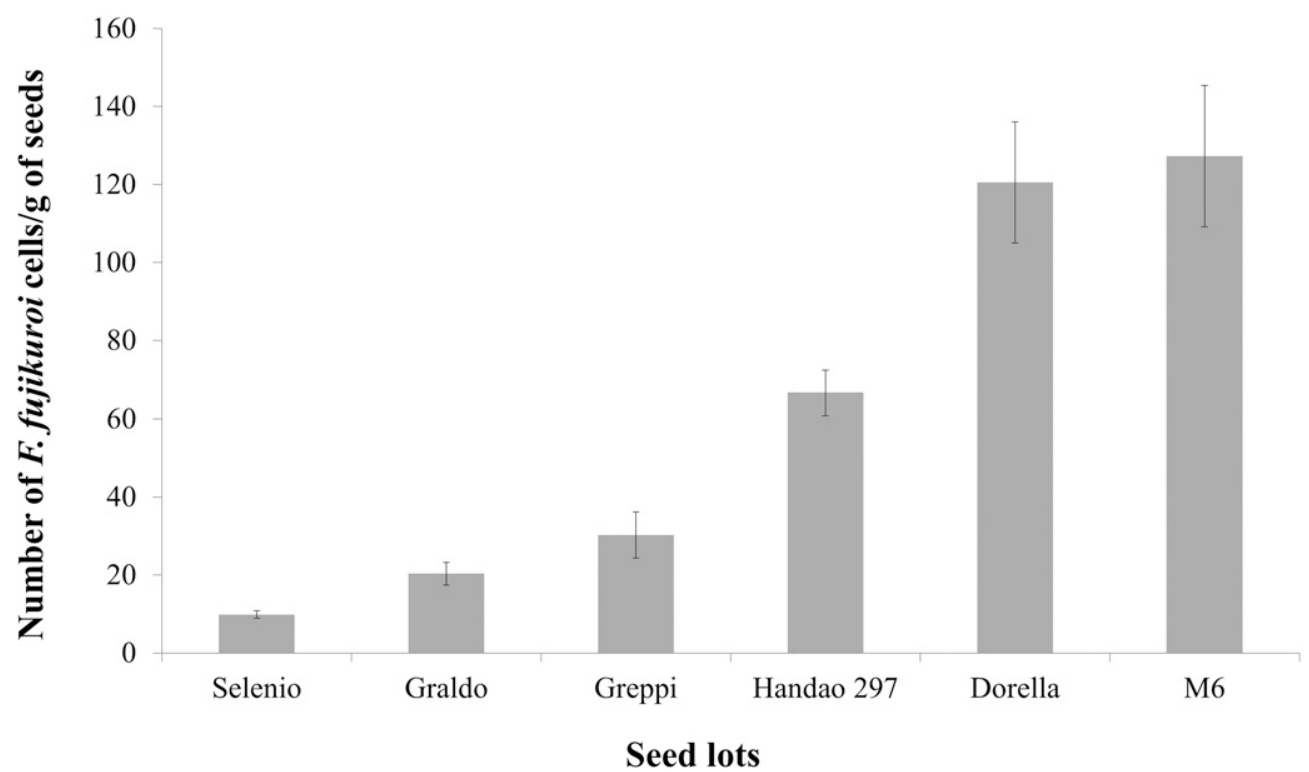

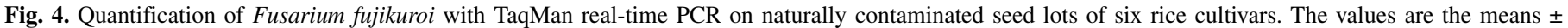
standard deviation ( $n=9$ independent analyses).

It was found that TaqMan real-time PCR, using a FfujiPq and TqF2/TqR primer-probe combination with a detection limit of $27.5 \mathrm{fg}$ of fungal DNA, had similar or higher sensitivity than TaqMan PCR assays that target other Fusarium spp. such as $F$. virguliforme (100 fg), $F$. verticillioides and $F$. proliferatum $(10$ pg), and F. culmorum and $F$. graminearum (0.9 pg) (Lin et al. 2014; Waalwijk et al. 2004; Wang et al. 2015). Furthermore, our TaqMan real-time PCR assay was around 364-fold more sensitive than the SYBR Green real-time PCR assay, which has a 10 pg detection limit of $F$. fujikuroi DNA (Amatulli et al. 2012).

The most abundant presence of $F$. fujikuroi during disease development was found in the roots and green tissues of the highly susceptible M6 cultivar, while the pathogen was present at lower concentrations in the roots of the other two susceptible cultivars. The higher fungal presence in M6 cultivar could be associated with a natural infection with $F$. fujikuroi $(17.2 \%)$ in the M6 seed lot, which was not found in the other tested cultivars. At $1 \mathrm{wpg}$, the pathogen was found to be more diffused in the green tissues and in the roots to a lesser extent, while at $3 \mathrm{wpg}$ the fungus was uniformly spread in the plant tissues and the difference between the roots and green tissues became negligible. The high presence of $F$. fujikuroi in the roots of rice plants should be considered to obtain more detailed knowledge on the epidemiology of bakanae disease. The results of the fungal quantification in this study match the results of a transcriptomic study of two cultivars (Dorella and Selenio) infected with $F$. fujikuroi (Matić et al. 2016), which indicated a higher presence of $F$. fujikuroi and its systemic distribution throughout the whole rice plants of susceptible cultivar Dorella. On the other hand, a lower concentration and local (aerial) distribution of $F$. fujikuroi was found in the resistant Selenio cultivar, without any visible damage to the plants.

In this study, it was possible to quantify F. fujikuroi DNA accurately over a large range of concentrations, using real-time PCR in complex biological matrices, including naturally contaminated and artificially inoculated rice samples of diverse origin, in which various microorganisms may coexist with the target species. In the case of naturally infected seeds, it is not possible to accurately distinguish the target pathogen from other Fusarium spp. associated with bakanae disease through the exclusive use of discriminative techniques, such as plating on culture media. Such a procedure is time consuming and delays the identification of $F$. fujikuroi until detailed microscopic observations of the morphological traits have been made (Munkvold 2009). Consequently, the
qPCR protocol developed to quantify $F$. fujikuroi may be considered a useful tool for the early detection of $F$. fujikuroi in rice seeds. The treatment of rice seeds is currently the most valuable tool to control bakanae disease. For small quantities, seed companies could choose to use thermal treatments with hot water $\left(60\right.$ to $65^{\circ} \mathrm{C}$ for $\left.15 \mathrm{~min}\right)$ or chemical treatments (Matić et al. 2014; Park et al. 2008). A chemical treatment is commonly used for larger seed quantities, but in recent years, the most important active ingredient (prochloraz) has been withdrawn from the market, and the effectiveness of other fungicides is not satisfactory. Therefore, it is of utmost importance to take into consideration possible alternatives (Matić et al. 2014). Seed companies could use this molecular tool before and after seed treatments against F. fujikuroi in order to test the efficacy of the treatments and to certify that the seed lots are free from $F$. fujikuroi.

\section{ACKNOWLEDGMENTS}

The research that has led to these results has received funding from the Seventh Framework Program (FP7/2007-2013) under Grant Agreement No 311875 "Seed health: development of seed treatment methods, evidence for seed transmission and assessment of seed health" (TESTA) and from the European Union Horizon 2020 research and innovation program under grant agreement number 634179 "Effective Management of Pests and Harmful Alien Species-Integrated Solutions" (EMPHASIS).

\section{LITERATURE CITED}

Adams, P. S. 2006. Data analysis and reporting. Pages 39-62 in: Real-Time PCR. M. Tevfik Dorak, ed. Taylor \& Francis, New York.

Amatulli, M. T., Spadaro, D., Gullino, M. L., and Garibaldi, A. 2010. Molecular identification of Fusarium spp. associated with bakanae disease of rice in Italy and assessment of their pathogenicity. Plant Pathol. 59:839-844.

Amatulli, M. T., Spadaro, D., Gullino, M. L., and Garibaldi, A. 2012. Conventional and real-time PCR for the identification of Fusarium fujikuroi and Fusarium proliferatum from diseased rice tissues and seeds. Eur. J. Plant Pathol. 134:401-408.

Capote, N., Pastrana, A. M., Aguado, A., and Sánchez-Torres, P. 2012. Molecular tools for detection of plant pathogenic fungi and fungicide resistance. Pages 151-202 in: Plant Pathology. C. J. Cumagun, ed. InTech.

Carter, L. L. A., Leslie, L. F., and Webster, R. K. 2008. Population structure of Fusarium fujikuroi from California rice and water grass. Phytopathology 98:992-998.

Deepak, S. A., Kottapalli, K. R., Rakwal, R., Oros, G., Rangappa, K. S., Iwahashi, H., Masuo, Y., and Agrawal, G. K. 2007. Real-time PCR: Revolutionizing detection and expression analysis of genes. Curr. Genomics 8:234-251. 
Desjardins, A. E., Manhanadhar, H. K., Plattner, R. D., Manandhar, G. G., Poling, S. M., and Maragos, C. M. 2000. Fusarium species from Nepalese rice and production of mycotoxins and gibberellic acid by selected species. Appl. Environ. Microbiol. 66:1020-1025.

Desjardins, A. E., Plattner, R. D., and Nelson, P. E. 1997. Production of fumonisin B1 and moniliformin by Gibberella fujikuroi from rice from various geographic areas. Appl. Environ. Microbiol. 63:1838-1842.

Dieter, K. 2002. Quantification using real-time PCR technology: Applications and limitations. Trends Mol. Med. 8:257-260.

EPPO. 2014. PM 7/98 (2) Specific requirements for laboratories preparing accreditation for a plant pest diagnostic activity. EPPO Bull. 44:117-147.

Fang, G., Hammar, S., and Grumet, R. 1992. A quick and inexpensive method for removing polysaccharides from plant genomic DNA. Biotechniques 13:52-54.

Gupta, A. K., Solanki, I. S., Bashyal, B. M., Singh, Y., and Srivastava, K. 2015. Bakanae of rice - an emerging disease in Asia. J. Anim. Plant Sci. 25: 1499-1514.

Hwang, I. S., Kang, W. R., Hwang, D. J., Bae, S. C., Yun, S. H., and Ahn, I. P. 2013. Evaluation of bakanae disease progression caused by Fusarium fujikuroi in Oryza sativa L. J. Microbiol. 51:858-865.

ISTA. 1985. International Seed Testing Association. International Seed Testing Association rule book. Seed Sci. Technol. 13:299-520.

Jeon, Y. A., Yu, S. H., Lee, Y. Y., Park, H. J., Lee, S., Sung, J. S., Kim, Y. G., and Lee, H. S. 2013. Incidence, molecular characteristics and pathogenicity of Gibberella fujikuroi species complex associated with rice seeds from Asian countries. Mycobiology 41:225-233.

Jeong, H., Lee, S., Choi, G. J., Lee, T., and Yun, S. H. 2013. Draft genome sequence of Fusarium fujikuroi B14, the causal agent of the bakanae disease of rice. Genome Announc. 1:e00035-13.

John, M. E. 1992. An efficient method for isolation of RNA and DNA from plants containing polyphenolics. Nucleic Acids Res. 20:2381.

Karov, I. K., Mitrev, S. K., and Kostadinovska, E. D. 2009. Gibberella fujikuroi (Sawada) Wollenweber, the new parasitical fungus on rice in the Republic of Macedonia. Proc. Nat. Sci. Matica Srpska Novi Sad 116:175-182.

Kermekchiev, M. B., Kirilova, L., Vail, E. E., and Barnes, W. M. 2009. Mutants of Taq DNA polymerase resistant to PCR inhibitors allow DNA amplification from whole blood and crude soil samples. Nucleic Acids Res. 37:e40.

Leslie, J. F., and Summerell, B. A. (eds.) 2006. The Fusarium Laboratory Manual. John Wiley \& Sons, Oxford, UK

Leslie, J. F., Zeller, K. A., Wohler, M., and Summerell, B. A. 2004. Interfertility of two mating populations in the Gibberella fujikuroi species complex. Eur. J. Plant Pathol. 110:611-618.

Lin, Z., Xu, S., Que, Y., Wang, J., Comstock, J. C., Wei, J., McCord, P. H., Chen, B., Chen, R., and Zhang, M. 2014. Species-specific detection and identification of Fusarium species complex, the causal agent of sugarcane pokkah boeng in China. PLoS One 9:e104195.

Matić, S., Bagnaresi, P., Biselli, C., Orru', L., Amaral Carneiro, G., Siciliano, I., Valé, G., Gullino, M. L., and Spadaro, D. 2016. Comparative transcriptome profiling of resistant and susceptible rice genotypes in response to the seedborne pathogen Fusarium fujikuroi. BMC Genomics 17:608.

Matić, S., Spadaro, D., Garibaldi, A., and Gullino, M. L. 2014. Antagonistic yeasts and thermotherapy as seed treatments to control Fusarium fujikuroi on rice. Biol. Control 73:59-67.

Matić, S., Spadaro, D., Prelle, A., Gullino, M. L., and Garibaldi, A. 2013. Light affects fumonisin production in strains of Fusarium fujikuroi, Fusarium proliferatum, and Fusarium verticillioides isolated from rice. Int. J. Food Microbiol. 166:515-523.

Mirmajlessi, S. M., Loit, E., Mänd, M., and Mansouripour, S. M. 2015. Realtime PCR applied to study on plant pathogens: potential applications in diagnosis-A review. Plant Prot. Sci. 4:177-190.

Misra, J. K., Merca, S. D., and Mew, T. W. 1994. Fungal pathogens. Pages 75-89 in: A Manual of Rice Seed Health Testing. T. W. Mew and J. K. Misra, eds. International Rice Research Institute, Los Baños, Philippines.

Mojica, J., and Gomez, K. A. 1994. Samples and sampling. Pages 17-21 in: A Manual of Rice Seed Health Testing. T. W. Mew and J. K. Misra, eds. International Rice Research Institute, Los Baños, Philippines.
Munkvold, G. P. 2009. Seed pathology progress in academia and industry. Annu. Rev. Phytopathol. 47:285-311.

O’Donnell, K., Cigelnik, E., and Nirenberg, H. I. 1998. Molecular systematics and phylogeography of the Gibberella fujikuroi species complex. Mycologia 90:465-493.

Ou, S. H. (ed.) 1985. Rice Diseases. Commonwealth. Mycological Institute, Kew, UK.

Park, W. S., Yeh, W. H., Lee, S. W., Han, S. S., Lee, J. S., Lim, C. K., and Lee, Y. H. 2008. Electron microscopic study for the influence of soaking in hot water and prochloraz solution on spore and mycelium of Fusarium fujikuroi infected in rice seed. Res. Plant Dis. 15:94-100.

Ruiz-Roldán, M. C., Köhli, M., Roncero, M. I., Philippsen, P., Di Pietro, A., and Espeso, E. A. 2010. Nuclear dynamics during germination, conidiation, and hyphal fusion of Fusarium oxysporum. Eukaryot. Cell 9:1216-1224.

Sambrook, J., and Russell, D. W. (eds.) 2001. Molecular Cloning: A Laboratory Manual. Cold Spring Harbor Laboratory, Cold Spring Harbor, NY.

Smith, C. J., and Osborn, A. M. 2009. Advantages and limitations of quantitative PCR (Q-PCR)-based approaches in microbial ecology. FEMS Microbiol. Ecol. 67:6-20.

Spadaro, D., Gullino, M. L., and Garibaldi, A. 2016. Recenti acquisizioni sulla malattia del riso provocata da Fusarium fujikuroi. Protezione Colture 9: 11-17.

Stowe, B. B., and Yamaki, T. 1957. The history and physiological action of the gibberellins. Annu. Rev. Plant Physiol. 8:181-216.

Tian, S., Nakamura, K., and Kayahara, H. 2004. Analysis of phenolic compounds in white rice, brown rice, and germinated brown rice. J. Agric. Food Chem. 52:4808-4813

Tinivella, F., Hirata, L. M., Celan, M. A., Wright, S. A. I., Amein, T., Schmitt, A., Koch, E., van der Wolf, J. M., Groot, S. P. C., Stephan, D., Garibaldi, A., and Gullino, M. L. 2009. Control of seed-borne pathogens on legumes by microbial and other alternative seed treatments. Eur. J. Plant Pathol. 123: 139-151.

Titone, P., Grassi, G., Polenghi, G., Tamborini, L., and Garibaldi, A. 2004. Concia del riso: Prodotti chimici e termoterapia a confronto. Inf. Fitopatol. 54:41-49.

Valasek, M. A., and Repa, J. J. 2005. The power of real-time PCR. Adv. Physiol. Educ. 29:151-159.

Waalwijk, C., van der Heide, R., de Vries, I., van der Lee, T., Schoen, C., Costrel-de Corainville, G., Häuser-Hahn, I., Kastelein, P., Köhl, J., Lonnet, P., Demarquet, T., and Kema, G. H. J. 2004. Quantitative detection of Fusarium species in wheat using TaqMan. Eur. J. Plant Pathol. 110:481494

Wang, G., Wang, G., Zhang, X., Wang, F., and Song, R. 2012. Isolation of high quality RNA from cereal seeds containing high levels of starch. Phytochem. Anal. 23:159-163.

Wang, J., Jacobs, J. L., Byrne, J. M., and Chilvers, M. I. 2015. Improved diagnoses and quantification of Fusarium virguliforme, causal agent of soybean sudden death syndrome. Phytopathology 105:378-387.

Webster, R. K., and Gunnell, P. S. (eds.) 1992. Compendium of Rice Diseases. American Phytopathological Society, St. Paul, MN.

Wiemann, P., Sieber, C. M. K., von Bargen, K. W., Studt, L., Niehaus, E., Espino, M., J. J., Huß, K., Michielse, C. B., Albermann, S., Wagner, D., Bergner, S. V., Connolly, L. R., Fischer, A., Reuter, G., Kleigrewe, K., Bald, T., Wingfield, B. D., Ophir, R., Freeman, S., Hippler, M., Smith, K. M., Brown, D. W., Proctor, R. H., Münsterkötter, M., Freitag, M., Humpf, H. U., Güldener, U., and Tudzynski, B. 2013. Deciphering the cryptic genome: genome-wide analyses of the rice pathogen Fusarium fujikuroi reveal complex regulation of secondary metabolism and novel metabolites. PLoS Pathog. 9:e1003475

Wulff, E. G., Sørensen, J. L., Lübeck, M., Nielsen, K. F., Thrane, U., and Torp, J. 2010. Fusarium spp. associated with rice Bakanae: Ecology, genetic diversity, pathogenicity and toxigenicity. Environ. Microbiol. 12:649-657.

Zhang, Y. J., Zhang, S., Liu, X. Z., Wen, H. A., and Wang, M. 2010. A simple method of genomic DNA extraction suitable for analysis of bulk fungal strains. Lett. Appl. Microbiol. 51:114-118. 